\title{
Photosynthetic carbon acquisition in the lichen photobionts Coccomyxa and Trebouxia (Chlorophyta)
}

\author{
Kristin Palmqvist, Asuncion de los Rios, Carmen Ascaso and Göran Samuelsson
}

\begin{abstract}
Palmqvist, K., de los Rios, A., Ascaso, C. and Samuelsson, G. 1997. Photosynthetic carbon acquisition in the lichen photobionts Coccomyxa and Trebouxia (Chlorophyta). - Physiol. Plant. 101: 67-76.
\end{abstract}

\begin{abstract}
Processes involved in photosynthetic $\mathrm{CO}_{2}$ acquisition were characterised for the isolated lichen photobiont Trebouxia erici (Chlorophyta, Trebouxiophyceae) and compared with Coccomyxa (Chlorophyta), a lichen photobiont without a photosynthetic $\mathrm{CO}_{2}$-concentrating mechanism. Comparisons of ultrastructure and immuno-gold labelling of ribulose-1,5-bisphosphate carboxylase-oxygenase (Rubisco; EC 4.1.1.39) showed that the chloroplast was larger in T. erici and that the majority of Rubisco was located in its centrally located pyrenoid. Coccomyxa had no pyrenoid and Rubisco was evenly distributed in its chloroplast. Both species preferred $\mathrm{CO}_{2}$ rather than $\mathrm{HCO}_{3}^{-}$ as an external substrate for photosynthesis, but T. erici was able to use $\mathrm{CO}_{2}$ concentrations below 10-12 $\mu M$ more efficiently than Coccomyxa. In T. erici, the lipid-insoluble carbonic anhydrase (CA; EC 4.2.1.1) inhibitor acetazolamide (AZA) inhibited photosynthesis at $\mathrm{CO}_{2}$ concentrations below $1 \mu \mathrm{M}$, while the lipid-soluble CA inhibitor ethoxyzolamide (EZA) inhibited $\mathrm{CO}_{2}$-dependent $\mathrm{O}_{2}$ evolution over the whole $\mathrm{CO}_{2}$ range. EZA inhibited photosynthesis also in Coccomyxa, but to a much lesser extent below 10-12 $\mu M \mathrm{CO}_{2}$. The internal CA activity of Trebouxia, per unit chlorophyll (Chl), was ca $10 \%$ of that of Coccomyxa. Internal CA activity was also detected in homogenates from $T$. erici and two Trebouxia-lichens (Lasallia hispanica and Cladina rangiferina). In all three, the predominating CA had $a$-type characteristics and was significantly inhibited by low concentrations of AZA, having an $\mathrm{I}_{50}$ below $10-20 \mathrm{nM}$. In Coccomyxa a $\beta$-type CA predominates, which is much less sensitive to AZA. Thus, the two photobionts differed in three major characteristics with respect to $\mathrm{CO}_{2}$ acquisition, the subcellular location of Rubisco, the relative requirement of CA and the biochemical characteristics of their predominating internal CA. These differences may be linked to the ability of Trebouxia to accumulate dissolved inorganic carbon internally, enhancing their $\mathrm{CO}_{2}$ use efficiency at and below air-equilibrium concentrations (10-12 $\left.\mu M \mathrm{CO}_{2}\right)$ in comparison with Coccomyxa.
\end{abstract}

Key words - Carbonic anhydrase, Coccomyxa, $\mathrm{CO}_{2}$-concentrating mechanism, green alga, immuno-gold labelling, lichen photobiont, photosynthesis, pyrenoid, Rubisco, Trebouxia erici.

K. Palmqvist (corresponding author,e-mail kristin.palmqvist@plantphys.umu.se) and G. Samuelsson, Dept of Plant Physiology, Umeå Univ., S-901 87 Umeå, Sweden; A. de los Rios and C. Ascaso, Centro de Ciencias Medioambientales (C.S.I.C.), Serrano 115 bis, E-28006, Madrid, Spain.

\section{Introduction}

Lichens are the symbiotic phenotype of nutritionally specialised fungi (mycobionts) that derive carbon nutrition from algal and/or cyanobacterial photobionts, located extracellulary within a matrix of fungal hyphae (Honegger 1991). The majority of lichens, about $90 \%$, have green algal photobionts, most of which belong to the class Trebouxiophyceae, a sister-taxon to Chlorophyceae within Chlorophyta (Friedl 1995). Trebouxia is the most frequent genus, being present in approximately $20 \%$ of all lichens, mainly within Lecanorales. Recent data, based on $18 \mathrm{~S}$ rRNA analysis, suggest that $\mathrm{Coc}$ comyxa should also be included within Trebouxio- 
phyceae (T. Friedl, Plant Ecology and Systematics, University Bayreuth, Germany, personal communication), a genus which is less common as lichen photobionts, occurring in the fungal families Baeomycetaceae, Peltigeraceae and in lichenised Basidiomycetes (Friedl and Büdel 1996). Trebouxia is rarely found free-living in nature, whereas Coccomyxa also comprises non-symbiotic species (Honegger 1991). The physiological integration between mycobiont and photobiont is moreover closer in lichens with Trebouxia photobionts compared to lichens with Coccomyxa (Honegger 1991).

Lichens are metabolically active when their water content is above a critical threshold level, which varies between species. The water content optimal for photosynthesis also varies, which is caused by several factors, including the morphology of the thallus and the ability of the photobiont to acquire and fix $\mathrm{CO}_{2}$ from an environment where $\mathrm{CO}_{2}$ diffusion is impeded (Lange et al. 1993). Cyanobacterial photobionts and algae with a pyrenoid in the chloroplast, such as Trebouxia spp. and some species in the genus Stichococcus, possess a photosynthetic $\mathrm{CO}_{2}$-concentrating mechanism (CCM) (Badger et al. 1993, Palmqvist 1993, Smith and Griffiths 1996a), which allows the cell to accumulate and maintain a higher concentration of dissolved inorganic carbon (DIC) inside the chloroplast in relation to the environment (Badger and Price 1994). However, a CCM in lichen photobionts has mainly been inferred from measurements of internal DIC pools, carboxylation efficiency of intact lichens and carbon isotope discrimination characteristics (Badger et al. 1993, Palmqvist 1993, Palmqvist et al. 1994b, Máguas et al. 1995, Smith and Griffiths 1996a) and the mechanistic details have not been resolved.

Coccomyxa and other species without a pyrenoid in the chloroplast, such as Trentepohlia and some other species of Stichococcus lack a CCM (Palmqvist 1993, Palmqvist et al. 1994a, Smith and Griffiths 1996a). Among these, Coccomyxa has been studied in more detail. This alga has a relatively more efficient Rubisco, compared to Chlamydomonas reinhardtii, an alga with a well developed CCM (Palmqvist et al. 1995). Moreover, Coccomyxa possesses high activity of an intracellular carbonic anhydrase (CA) of $\beta$-type (Hiltonen et al. 1995), not found in $C$. reinhardtii, which, similar to other $\beta$-type CAs has a relatively low sensitivity to CA inhibitors (Hewett-Emmett and Tashian 1996). It is not clear, however, to what extent this $\mathrm{CA}$ is involved in photosynthetic $\mathrm{CO}_{2}$ acquisition in Coccomyxa (Palmqvist et al. 1995).

In contrast to this, numerous studies have established an important role of different $\mathrm{CA}$ isozymes in the $\mathrm{CO}_{2}$ acquisition process of algae with a CCM (Badger and Price 1994). Among these, a low $\mathrm{CO}_{2}$-induced periplasmic CA has been particularly well characterised (Coleman et al. 1984, Fukuzawa et al. 1990), even though internal CAs are also involved in the CCM (Karlsson et al. 1995, Eriksson et al. 1996). Attempts have been made to detect and quantify the activity of both internal and periplasmic CA also in Trebouxia and Trebouxia-lichens (Badger et. al 1993, Palmqvist et al. 1994b). So far, however, it was only the extremely sensitive mass spectrometer method, measuring ${ }^{18} \mathrm{O}$ exchange in vivo, that succeeded in detecting any CA activity in these. However, due to the complexity of in vivo systems the latter results were difficult to interpret (Palmqvist and Badger 1996).

This study aimed at characterising mechanisms involved in photosynthetic $\mathrm{CO}_{2}$ acquisition, including $\mathrm{CA}$, in an isolated strain of Trebouxia, to avoid the complexity of the intact lichen system. Some measurements were, however, performed also with intact Trebouxia-lichens to see whether the results obtained from the isolated alga were valid for lichenised cells. The results are compared with new and previous data from both isolated and lichenised Coccomyxa with the aim of characterising differences and similarities in $\mathrm{CO}_{2}$ acquisition between the two photobionts and to see the extent of different components affecting their photosynthetic physiology.

Abbreviations - AZA, acetazolamide (5-acetamido-1,3-thiadiazole-2-sulfonamide); BBM, Bold's basal medium; BTP, 1,3-bis[tris(hydroxymethyl)methylamino]propane; CA, carbonic anhydrase (EC 4.2.1.1); $\mathrm{CCM}, \mathrm{CO}_{2}$-concentrating mechanism; $\mathrm{CO}_{2}(\mathrm{aq}), \mathrm{CO}_{2}$ dissolved in aqueous solution; Chl, chlorophyll; EPPS, N-(2-hydroxyethyl)piperazine-N'-(3-propanesulfonic acid); EZA, ethoxyzolamide (6-ethoxy-2-benzo-thiazole-2-sulfonamide); DIC, dissolved inorganic carbon $\left(\mathrm{CO}_{2}+\right.$ $\left.\mathrm{HCO}_{3}^{-}\right) ; \mathrm{I}_{50}$, concentration required to obtain $50 \%$ inhibition of an enzyme activity; Rubisco, ribulose-1,5-bisphosphate carboxylase-oxygenase (EC 4.1.1.39).

\section{Materials and methods}

\section{Collection of lichen material and growth of algae}

Cladina rangiferina $(\mathrm{L}$.) Wigg. was collected near Umeå University, Umeå, Sweden in October and November 1995 and used for enzyme preparations immediately after collection. Lasallia hispanica (Frey) Sancho \& Crespo was collected in October 1995 in Sierra de Guadarrama, Madrid, Spain in their dry state. These samples were stored dry in darkness during transport and kept dry and dark in a cold room $\left(4^{\circ} \mathrm{C}\right)$ in the Umea laboratory prior to reactivation and experimental use. Peltigera aphthosa (L.) Willd. was collected outside Botsmark, Västerbotten, Sweden in August 1995, dried, stored and reactivated as specified in Palmqvist (1993).

Trebouxia erici (IB 364) was obtained from the algal collection in Innsbruck, Austria. Liquid cultures were grown in 0.5-1 glass bottles at $20^{\circ} \mathrm{C}$ in Bold's basal medium (BBM) (Nichols and Bold 1965) and continuously irradiated $\left(80 \mu \mathrm{mol} \mathrm{m} \mathrm{m}^{-2} \mathrm{~s}^{-1}\right)$ with a bank of fluorescent tubes (TL 20W/55, Philips, Eindhoven, The Netherlands). The cultures were bubbled with ambient air (35 $\mathrm{Pa} \mathrm{CO}_{2}$ ), stirred with a magnetic stirrer to obtain a homogenous distribution of cells $\left(5-10 \mu \mathrm{g} \mathrm{Chl} \mathrm{ml}{ }^{-1}\right)$ and diluted every week with fresh medium. Cells were also 

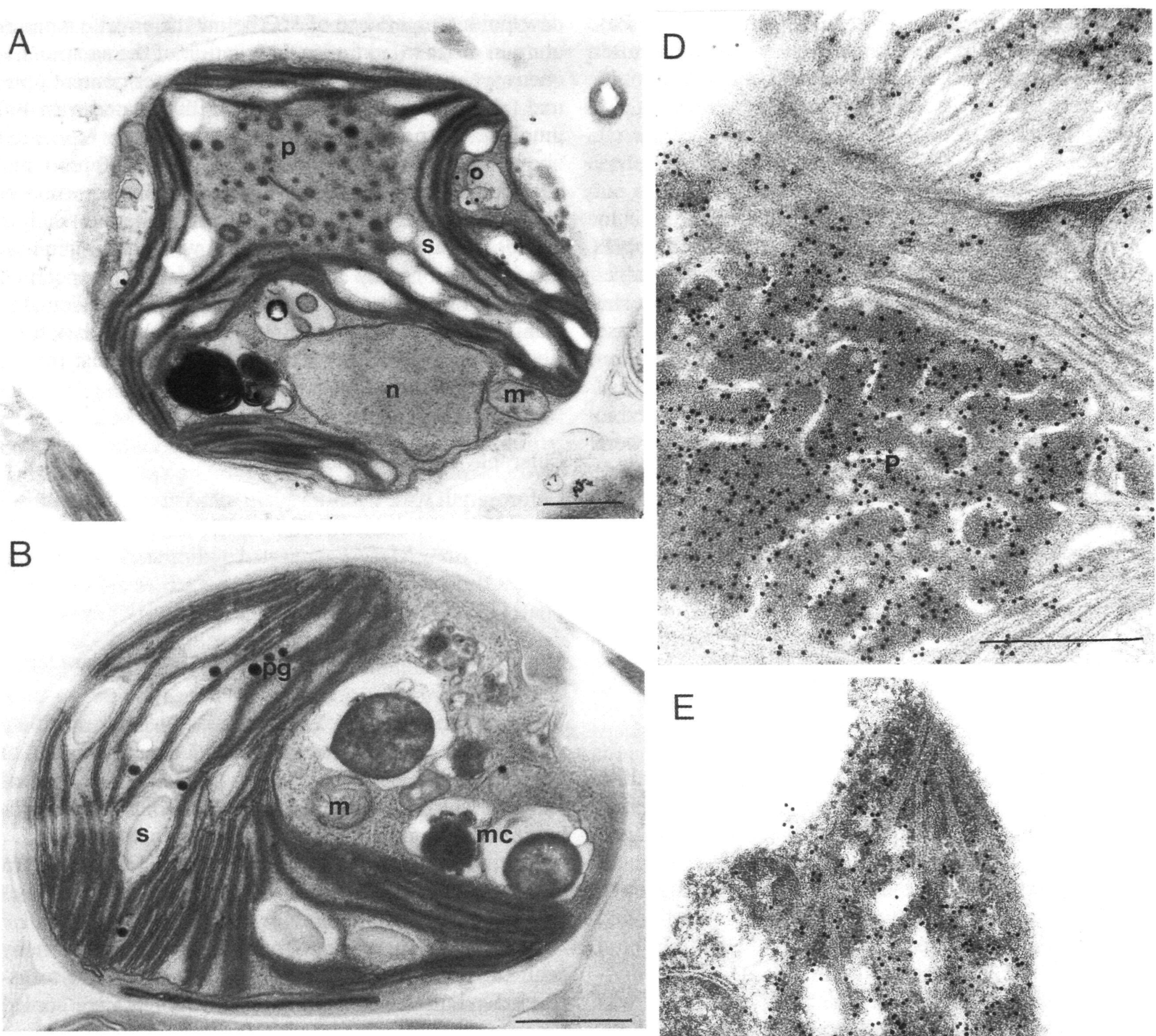

C
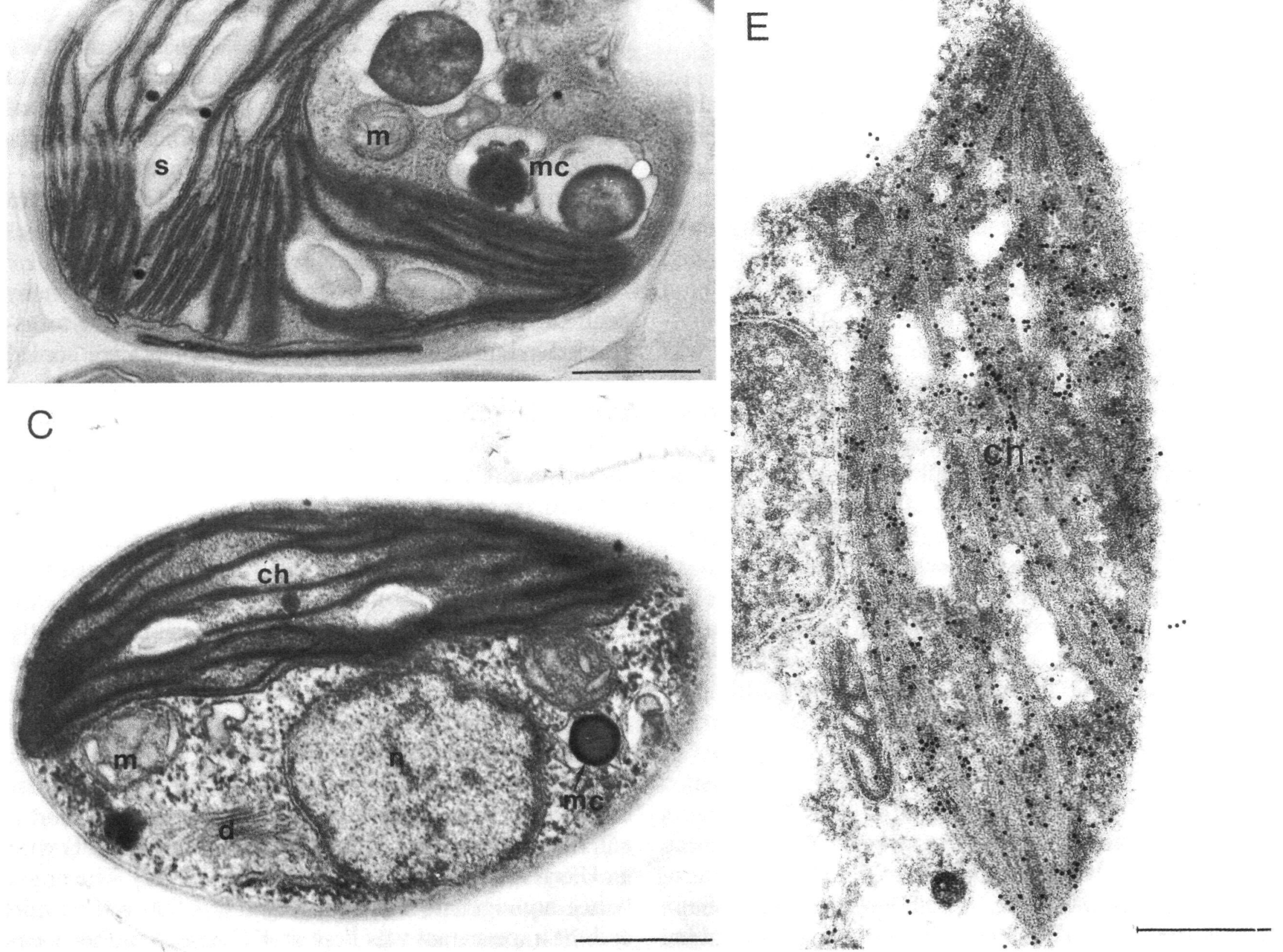

Fig. 1. Electron micrographs with the ultrastructure of free-living T. erici (A), Coccomyxa in Peltigera aphthosa (B) and free-living Coccomyxa (C). Plates D and E show free-living T. erici (D) and Coccomyxa (E) labelled with anti-Rubisco. d, Dictyosome; $\mathrm{p}$, pyrenoid; s, starch; m, mitochondria; $n$, nuclei; ch, chloroplast; mc, multivesicular complex; pg, plastoglobuli. $\mathrm{Bar}=0.5 \mu \mathrm{m}$. 
containing washed disrupted fungal hyphae and some intact algal cells was discarded, while the supernatant was pooled with the first supernatant. The CA activity was measured and related to the Chl content of the pooled homogenate. Thereafter, the homogenate was centrifuged at $17000 \mathrm{~g}$ for $15 \mathrm{~min}$. Again, most of the activity was recovered in the pellet although a small amount of CA was present in the soluble fraction, as in T. erici (see above). The pellet was treated as T. erici to solubilise the CA, but the ultracentrifugation was replaced by a lower speed centrifugation at $12500 \mathrm{~g}$ for $15 \mathrm{~min}$. The final supernatant was used to determine the AZA inhibition characteristics.

\section{Results}

Ultrastructure and distribution of Rubisco in Trebouxia and Coccomyxa

T. erici was characterised by a large and highly lobed chloroplast, with thylakoid lamellae, mainly consisting of grana stacks extending throughout the stroma. A pyrenoid with numerous and large pyrenoglobuli was present in the centre of the chloroplast. These were associated with short, single thylakoids extending from grana stacks in the stroma (Fig. 1A).

The free-living cells of Coccomyxa were characterised by a parietal, single, chloroplast without any signs of a pyrenoid (Fig. 1C). The chloroplast of Coccomyxa was moreover proportionally smaller in relation to the protoplast, compared to $T$. erici. The thylakoids were either single or piled up to form grana stacks similar to the observations of Peveling and Galun (1976). In lichenised Coccomyxa, the chloroplast was cup-shaped and more developed, compared to the free-living cells, occupying a proportionally larger volume of the protoplast and with more starch and plastoglobuli between its thylakoids (Fig. 1B). Multivesicular complexes were present in both free-living and lichenised Coccomyxa (Fig. 1B,C). In the lichenised Coccomyxa, these areas could contain both vesicles and storage bodies (Fig. 1B), while in the free-living cells, the areas of multivesicular complexes only contained black storage bodies (Fig. 1C).

When the location of Rubisco was compared between T. erici and Coccomyxa there were clear differences between the two species. In Coccomyxa, Rubisco was evenly distributed throughout the stromal part of the chloroplast (Fig. 1E). In T. erici, the highest concentration of Rubisco was found in the pyrenoid even though some gold particles were also present in the stroma (Fig. 1D), similar to previous observations of lichenised Trebouxia (Ascaso et al. 1995, Balaguer et al. 1996).

\section{DIC and $\mathrm{CO}_{2}$ responses of Trebouxia and Coccomyxa}

Figure $2 \mathrm{~A}, \mathrm{~B}$ shows the photosynthetic $\mathrm{CO}_{2}$ and $\mathrm{HCO}_{3}^{-}$ responses of $T$. erici measured at two $\mathrm{pH}$ values, 6.2 and 7.9 , respectively. At the lower $\mathrm{pH}$, photosynthesis was

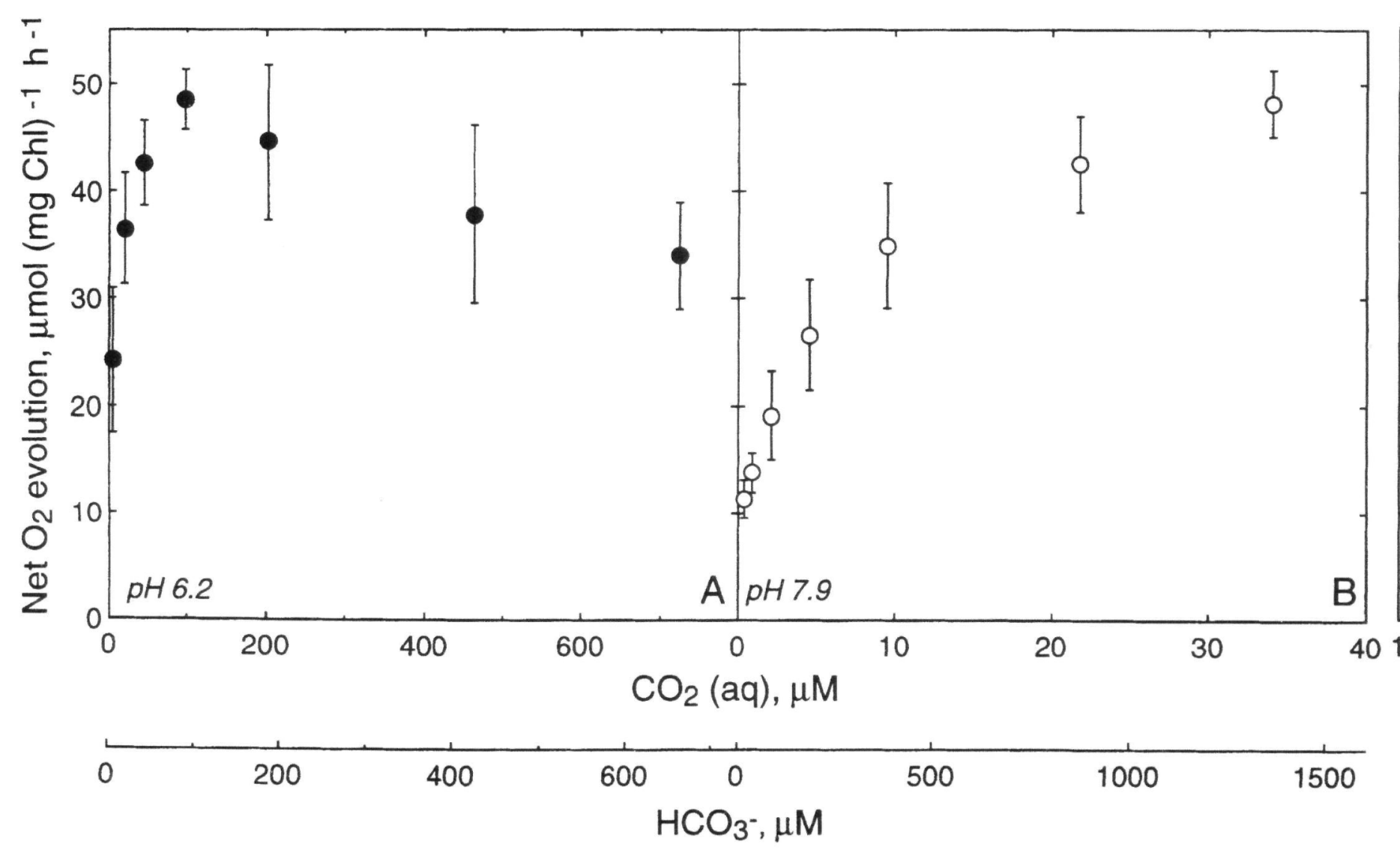

Fig. 2. Net rate of photosynthetic $\mathrm{O}_{2}$ evolution as a function of $\mathrm{HCO}_{3}^{-}$(lower x-axis) or $\mathrm{CO}_{2}$ (aq) (upper x-axis) in cultured cells of $T$. erici. The measurements were carried out at $25^{\circ} \mathrm{C}$ and light saturation $\left(200 \mu \mathrm{mol} \mathrm{m} \mathrm{m}^{-2} \mathrm{~s}^{-1}\right)$ in BBM-BTP medium at pH $6.2(\mathrm{~A})(-)$ or $\mathrm{pH} 7.9$ (B) (O) with controlled additions of $\mathrm{HCO}_{3}^{-}$to DIC-depleted medium. The $\mathrm{CO}_{2}$ and $\mathrm{HCO}_{3}^{-}$concentrations were calculated as in Palmqvist (1993). Data represent the average \pm SE of at least three independent experimental series. In C, (+) and solid line shows data obtained in a similar way for cultured cells of Coccomyxa (Palmqvist 1993, Palmqvist et al. 1994a) compared with the T. erici data obtained at the two $\mathrm{pH}$ values. 
saturated when both $\mathrm{CO}_{2}$ and $\mathrm{HCO}_{3}^{-}$was about $100 \mu M$, respectively, with a significant decline above $200 \mu M$ $\mathrm{CO}_{2}$ and/or $\mathrm{HCO}_{3}^{-}$(Fig. 2A). The reason for this decline is not clear, but a similar response has previously been observed also for higher plant leaves, at even lower concentrations of $\mathrm{CO}_{2}$ (Ögren and Evans 1993). Interestingly though, as $200 \mu M \mathrm{CO}_{2}$ (aq), corresponds to ca 500 $\mathrm{PaCO} \mathrm{CO}_{2}(\mathrm{~g})$, this decline in photosynthetic capacity at suprasaturating DIC concentrations might explain the failure to grow T. erici with $\mathrm{CO}_{2}$-enriched (1000-2000 Pa) air (see Materials and methods).

At the higher $\mathrm{pH}$, photosynthesis was saturated at a somewhat lower concentration of $\mathrm{CO}_{2}(40 \mu M)$, but at a considerably higher concentration of $\mathrm{HCO}_{3}^{-}(1500 \mu M)$ (Fig. 2B). Thus, since the affinity to low concentrations of $\mathrm{CO}_{2}$ was similar irrespective of $\mathrm{pH}$ (Fig. 2C), while the affinity to $\mathrm{HCO}_{3}^{-}$was strikingly different (Fig. 2A, B), it may hence be concluded that $T$. erici appears to prefer $\mathrm{CO}_{2}$ over $\mathrm{HCO}_{3}^{-}$as an external substrate for photosynthesis. However, since photosynthesis was saturated at a somewhat lower $\mathrm{CO}_{2}$ concentration at the higher $\mathrm{pH}$, this also suggests that $T$. erici may have the ability to use some $\mathrm{HCO}_{3}^{-}$as an external carbon source. The affinity to $\mathrm{CO}_{2}$ was moreover higher for $T$. erici as compared to Coccomyxa (Fig. 2C).

Incubation of $T$. erici with the lipid-insoluble CA inhibitor acetazolamide (AZA) resulted in more than $50 \%$ inhibition of net photosynthesis below $1 \mu M \mathrm{CO}_{2}$ (Fig.

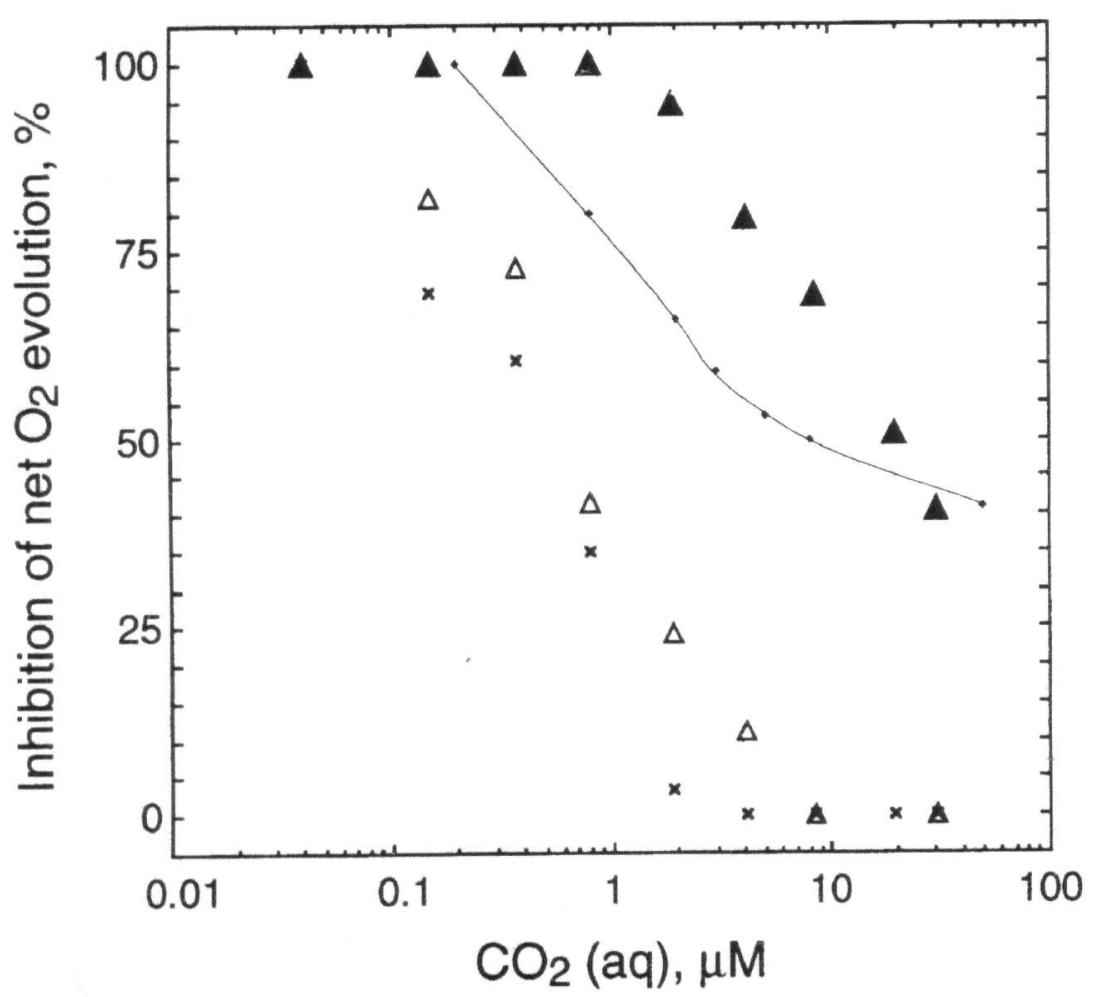

Fig. 3. Effects of the CA inhibitors AZA $(\times=5 \mu M ; \triangle=30 \mu M)$ and EZA $(\boldsymbol{\Delta}=350 \mu M)$ on photosynthetic net $\mathrm{O}_{2}$ evolution as a function of $\mathrm{CO}_{2}$ in $T$. erici. The measurements were carried out at $25^{\circ} \mathrm{C}$ and light saturation $\left(200 \mu \mathrm{mol} \mathrm{m} \mathrm{m}^{-2} \mathrm{~s}^{-1}\right)$ in BBM-BTP medium ( $\mathrm{pH}$ 7.9) with controlled additions of $\mathrm{HCO}_{3}^{-}$to DIC-depleted medium. The $\mathrm{CO}_{2}$ concentrations were calculated as in Palmqvist (1993). Data represent the average of two independent experimental series with each inhibitor concentration and compared with un-inhibited samples. The solid line shows data obtained for cultured cells of Coccomyxa using $500 \mu M$ EZA (Palmqvist et al. 1994a).
3 ), indicating the participation of a periplasmic CA in this alga, a possibility which will be discussed below. In the presence of the lipid-soluble CA inhibitor ethoxyzolamide (350 $\mu M$ EZA), photosynthesis was even more affected, with a $100 \%$ inhibition below $1 \mu M \mathrm{CO}_{2}$. This inhibition gradually declined to about $50 \%$ at air concentrations of $\mathrm{CO}_{2}$ (Fig. 3). In Coccomyxa, the effect of EZA was less severe, particularly at the lowest $\mathrm{CO}_{2}$ concentrations (Fig. 3), even though a higher concentration of the inhibitor was used $(500 \mu M)$.

Photosynthetic $\mathrm{CO}_{2}$ fixation in relation to external $\mathrm{CO}_{2}$ was also measured in intact thalli of the Trebouxia-lichen Lasallia hispanica (Fig. 4). Similar to $T$. erici there was a decrease in photosynthesis at high $\mathrm{CO}_{2}$ concentrations also in the lichen, as well as inhibition of photosynthesis in the presence of EZA. This inhibition decreased with increasing $\mathrm{CO}_{2}$, similar to what has previously been shown for another Trebouxia-lichen, Hypogymnia physodes (Badger et al. 1993).

\section{The relationship between photosynthetic capacity and DIC pool sizes in Trebouxia and Trebouxia-lichens}

Trebouxia-lichens accumulate an internal pool of DIC, which has been taken as evidence for the presence of a CCM in this genus (Badger et al. 1993, Palmqvist et al. 1994b, Smith and Griffiths 1996a). EZA increases the size of this pool, suggesting the involvement of a CA

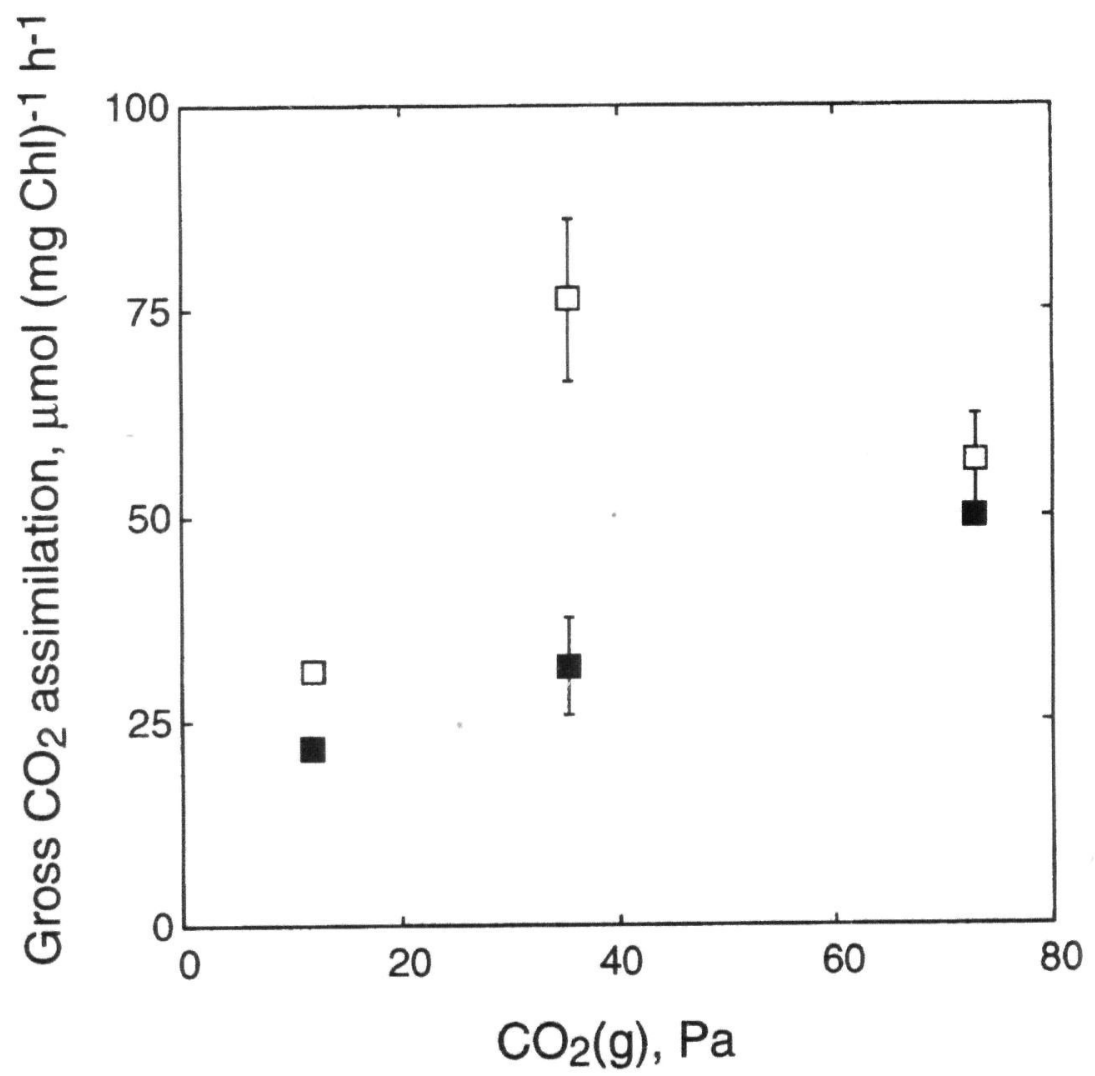

Fig. 4. Gross rate of $\mathrm{CO}_{2}$ assimilation in relation to external $\mathrm{CO}_{2}(\mathrm{~g})$ in the Trebouxia-lichen Lasallia hispanica. Measurements were carried out at $15^{\circ} \mathrm{C}$ and light saturation $(400 \mu \mathrm{mol}$ $\mathrm{m}^{-2} \mathrm{~s}^{-1}$ ). Samples were incubated in $20 \mathrm{~m} M$ EPPS buffer, $\mathrm{pH} 8.0$ (control, $\square$ ), or in $20 \mathrm{mM}$ EPPS buffer, pH 8.0 with $500 \mu M$ EZA (-) prior to measurements as detailed in Palmqvist and Badger (1996). Error bars ( \pm SD) are indicated when they exceed the symbol size; $n \geq 2$ for each series. 


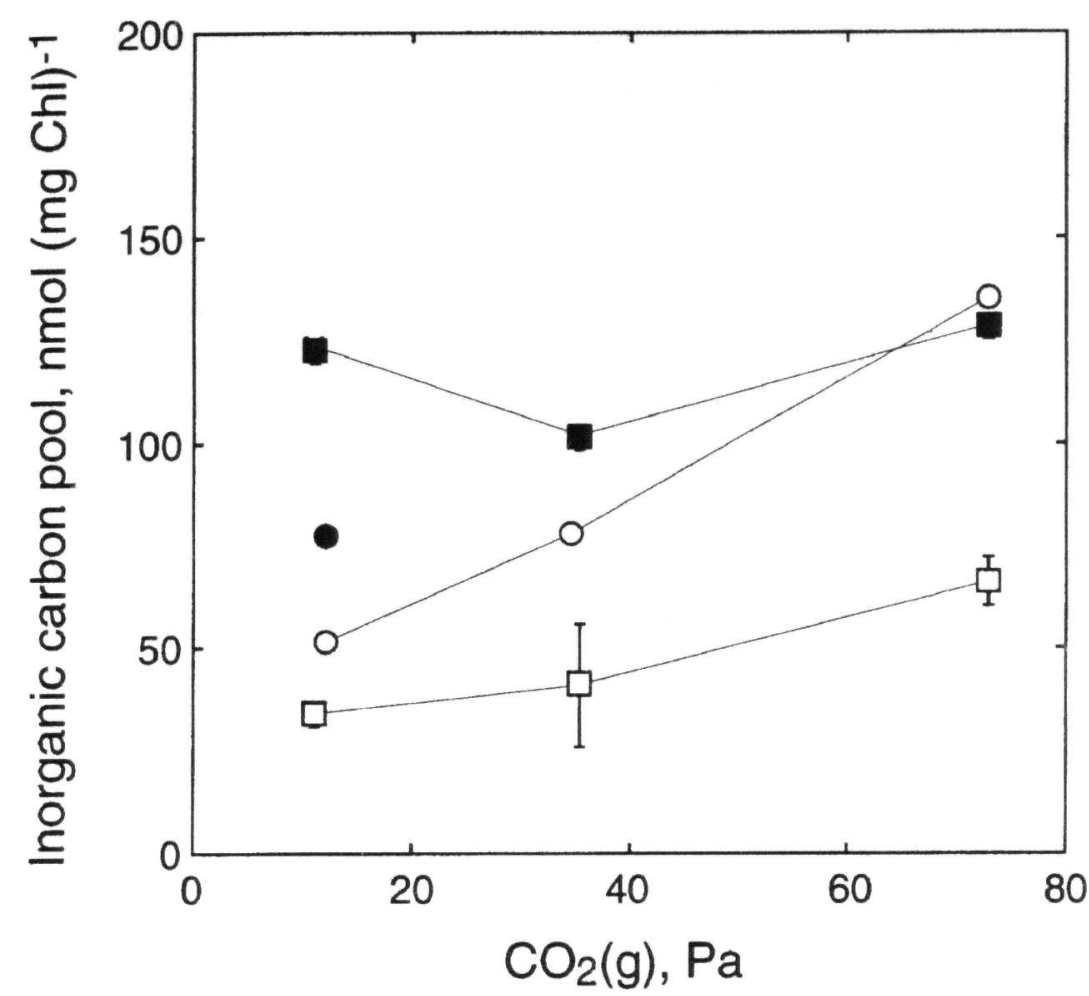

Fig. 5. Initial DIC pool size in relation to external $\mathrm{CO}_{2}(\mathrm{~g})$ in $T$. erici filtered onto a glass fiber filter and in intact thalli of $L$. hispanica. Samples were incubated in BBM growth medium ( $T$. erici, $\bigcirc$ ) or in $20 \mathrm{mM}$ EPPS buffer, $\mathrm{pH} 8.0$ (L. hispanica, $\square$ ), or in the same medium/buffer with $500 \mu M$ EZA prior to measurements: T. erici $(-$ ), L. hispanica $(\mathbf{\square})$. Lichens were measured at $15^{\circ} \mathrm{C}$ and $400 \mu \mathrm{mol} \mathrm{m}^{-2} \mathrm{~s}^{-1}$ and algae at $25^{\circ} \mathrm{C}$ and $200 \mu \mathrm{mol} \mathrm{m}$ $\mathrm{s}^{-1}$. Error bars $( \pm \mathrm{SD})$ are indicated when they exceed the symbol size; $\mathrm{n} \geq 2$ for each series

somewhere between the DIC pool and $\mathrm{CO}_{2}$ fixation by Rubisco (Badger et al. 1993, Palmqvist et al. 1994b). These characteristics were also found in $T$. erici and $L$. hispanica, where the size of the DIC pool was increased both with increasing $\mathrm{CO}_{2}$ and in the presence of EZA (Fig. 5).

Overall, however, the internal DIC pool of Trebouxia and Trebouxia-lichens, is relatively small when compared to free-living cyanobacteria (reviewed in Badger and Price 1994), cyanobacterial Nostoc-lichens (Badger et al. 1993, Sundberg et al. 1996) and C. reinhardtii (Badger et al. 1980). This includes both the absolute size of the pool and its size in relation to photosynthetic rate. The latter relation may be quantified by dividing the size of the pool with the steady-state $\mathrm{CO}_{2}$ fixation rate, measured under the same experimental conditions. This gives an estimate of the duration (in seconds) for which the pool would theoretically support photosynthetic $\mathrm{CO}_{2}$ fixation with substrate (Tab. 1). In a Nostoc-lichen, the pool would theoretically support photosynthesis for about $35 \mathrm{~s}$, while it would last for about $3-4 \mathrm{~s}$ in $T$. erici and Trebouxia-lichens. In the presence of EZA, the pool would last for about $8 \mathrm{~s}$ in Trebouxia and for about $17 \mathrm{~s}$ in C. reinhardtii (Tab. 1). Coccomyxa also appears to accumulate a small pool upon illumination (Tab. 1). However, using the same assumptions and calculations as in Badger et al. (1993), this pool corresponds to passive accumulation of DIC related to alkalisation of the chloroplast stroma upon illumination.

\section{Evidence for the presence of internal $a$-CA in Trebouxia and Trebouxia-lichens}

The data presented in Fig. 3 indicate that both intracellular and periplasmic CA participate in photosynthetic $\mathrm{CO}_{2}$ acquisition in Trebouxia. Despite this, it was not possible to detect any CA activity in washed and concentrated intact $T$. erici cells, suggesting that the effect of AZA (Fig. 3) may be caused by penetration of the inhibitor to internal CA. Indeed, internal CA activity could be found and quantified in crude homogenates of T. erici, L. hispanica and $C$. rangiferina, another Trebouxia-lichen (Tab. 2). In all three, the CA activity was somewhat higher, expressed per unit Chl, compared to the internal activity of C. reinhardtii, but significantly lower than the total CA activity, including periplasmic $\mathrm{CA}$, of low- $\mathrm{CO}_{2}$ grown $C$. reinhardtii (Tab. 2). The CA activity of Trebouxia was though considerably lower than that of both free-living and lichenised Coccomyxa (Tab. 2).

Most of the CA was found in the insoluble fraction after centrifugation (see Materials and methods). This fraction was separated on a protein gel and tested against antibodies raised towards the intracellular $\beta$-CA of $\mathrm{Coc}$ comyxa (Hiltonen et al. 1995) and a chloroplast $\alpha$-CA from Chlamydomonas (Karlsson et al. 1995). However, there was no immunological cross-reaction between any of these and the Trebouxia CA/CAs (results not shown).

Tab. 1. The ratio (s) of DIC pool sizes (nmol $[\mathrm{mg} \mathrm{Chl}]^{-1}$ ) to $\mathrm{CO}_{2}$ assimilation rates (nmol $[\mathrm{mg} \mathrm{Chl}]^{-1} \mathrm{~s}^{-1}$ ) for T. erici and L. hispanica compared with literature data on five Trebouxia-lichens, five Coccomyxa-lichens, six Nostoc-lichens and low-CO $\mathrm{C}_{2} \mathrm{grown}_{\text {C. }}$ reinhardtii. All rates were obtained at light saturation of photosynthesis. DIC pool sizes and EZA inhibition were obtained as detailed in the respective studies. Data represent the average $\pm \mathrm{SE}$ for $[\mathrm{n}]$ number of comparable experiments at $\mathrm{CO}_{2}$ concentrations below saturation of both DIC accumulation and photosynthesis. All data from lichens with the same photobiont genus were pooled; ${ }^{1}$ Badger et al. $1993,{ }^{2}$ Palmqvist et al. 1994b, ${ }^{3}$ Smith and Griffiths 1996a, ${ }^{4}$ Sundberg et al. 1997. PD, pool decreases.

\begin{tabular}{|c|c|c|c|c|c|c|}
\hline Species & $\begin{array}{c}\text { Control } \\
\text { (s) }\end{array}$ & {$[\mathrm{n}]$} & $\begin{array}{c}\text { EZA } \\
(\mathrm{s})\end{array}$ & {$[\mathrm{n}]$} & $\begin{array}{c}\mathrm{AZA} \\
(\mathrm{s})\end{array}$ & [n] \\
\hline $\begin{array}{l}\text { T. erici } \\
\text { L. hispanica } \\
\text { C. reinhardtii }{ }^{2} \\
\text { Coccomyxa-lichens } s^{2,3} \\
\text { Trebouxia-lichens } \text { s., }^{1,3} \\
\text { Nostoc-lichens }\end{array}$ & $\begin{array}{c}4.2 \pm 0.5 \\
3.6 \pm 1.1 \\
\text { No pool } \\
1.5 \pm 0.6 \\
3.1 \pm 0.2 \\
34.5 \pm 5.8\end{array}$ & $\begin{array}{l}{[8]} \\
{[3]} \\
{[5]} \\
{[8]} \\
{[6]}\end{array}$ & $\begin{array}{l}8.7 \\
12.8 \pm 4.6 \\
17.2 \\
0.8 \pm 0.4 \\
8.3 \pm 0.6 \\
\mathrm{PD}^{1}\end{array}$ & $\begin{array}{l}{[1]} \\
{[3]} \\
{[1]} \\
{[4]} \\
{[7]}\end{array}$ & $\begin{array}{l}4.1 \\
3.2 \pm 2.1 \\
\text { No data } \\
\text { No data } \\
\text { No data }\end{array}$ & $\begin{array}{l}{[1]} \\
{[2]}\end{array}$ \\
\hline
\end{tabular}


Tab. 2. Carbonic anhydrase activity, expressed as Wilbur-Andersson units [WAU $=\left(\mathrm{t}_{0}-\mathrm{t}\right) / \mathrm{t}$ ] measured and calculated as defined in Materials and methods for cell extracts of T. erici, L. hispanica and $C$. rangiferina. Data is compared with data obtained in the same experimental set-up for Coccomyxa and $C$. reinhardtii. Data represent average \pm SE of $[n]$ independent enzyme preparations from each species; ${ }^{1}$ Palmqvist et al. 1994b, ${ }^{2}$ Palmqvist et al. 1990.

\begin{tabular}{lcc}
\hline Species & $\begin{array}{c}\text { CA activity } \\
\text { (WAU [mg Chl }]^{-1} \text { ) }\end{array}$ & [n] \\
\hline T. erici & $24.0 \pm 2.3$ & {$[2]$} \\
C. rangiferina & 8.0 & {$[1]$} \\
L. hispanica & $25.7 \pm 6.7$ & {$[3]$} \\
Coccomyxa $^{1}$ & 300 & \\
Coccomyxa-lichens $^{1}$ & $85-110$ & \\
C. reinhardtii & 60 (tot) & \\
C. reinhardtii & 3 (internal) & \\
\hline
\end{tabular}

The sulfonamide inhibition characteristics though indicate that an $a$-type CA predominates with an $\mathrm{I}_{50}$ of about 10-20 nM AZA in T. erici and C. rangiferina. In L. hispanica, the CA was even more sensitive to AZA inhibition, with an $\mathrm{I}_{50}$ below $3 \mathrm{n} M$ (Fig. 6). The high sensitivity of the internal CA of Trebouxia gives further support to the idea that the AZA effect on photosynthesis (Fig. 3 ) could reflect penetration of this inhibitor into the cell.

\section{Discussion}

\section{The two photobionts acquire $\mathrm{CO}_{2}$ differently}

Based on physiological measurements and experiments mainly conducted with intact lichens it has been proposed that photosynthetic $\mathrm{CO}_{2}$ acquisition may be differently organised in the two lichen photobionts Coccomyxa and Trebouxia (Palmqvist 1993, Palmqvist et al. 1994b, Máguas et al. 1995, Smith and Griffiths 1996a).

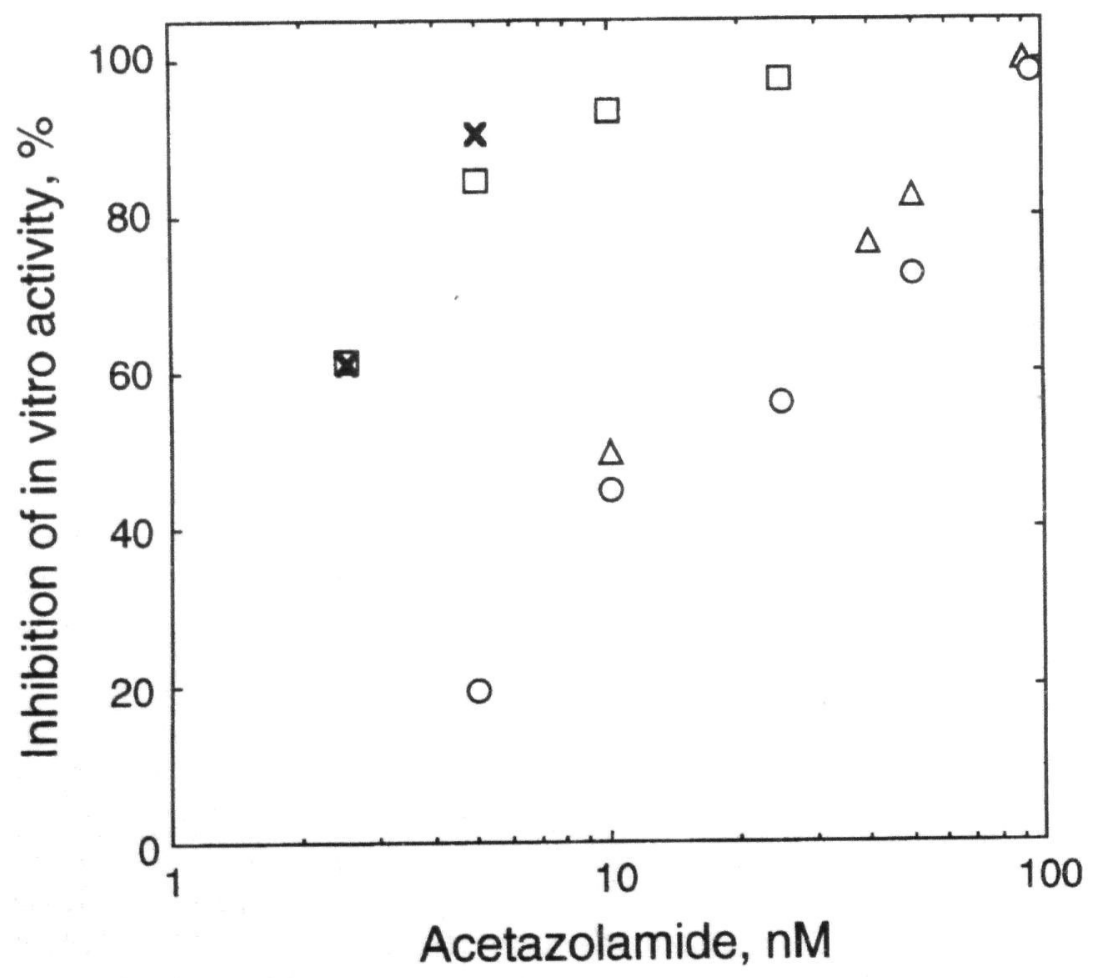

Fig. 6. Acetazolamide inhibition of in vitro CA activity in $T$. erici $(O), C$. rangiferina $(\triangle)$ and in two independent extractions of L. hispanica $(\square, \times)$.
The data presented here give substantial support to this hypothesis, as judged from the different localisation of Rubisco in the two photobionts (Fig. 1, Ascaso et al. 1995, Balaguer et al. 1996), the differences in relative requirement and biochemical characteristics of their internal CA:s (Figs 3 and 7, Hiltonen et al. 1995, Palmqvist et al. 1995) and the larger internal DIC pool in Trebouxia (Tab. 1). Indeed, the pyrenoid location of Rubisco, the relatively high requirement of CA and the corresponding ability to actively accumulate DIC, support the hypothesis that photosynthetic $\mathrm{CO}_{2}$ acquisition in Trebouxia is similar to that of other green algae with a CCM, such as Chlamydomonas, Chlorella and Scenedesmus (cf. Badger and Price 1994).

\section{The CCM of Trebouxia in relation to the CCM of other green algae}

However, there are some conspicuous differences between Trebouxia and the free-living algae with a CCM. First, the internal DIC pool appeared to be relatively smaller than in for instance $C$. reinhardtii (Tab. 1). The size of the DIC pool is determined by several factors, including the efficiency of the transport and accumulation system, the size of the chloroplast and/or cell, the rate of $\mathrm{HCO}_{3}^{-}$dehydration as well as the efficiency of Rubisco to fix $\mathrm{CO}_{2}$. Therefore, the smaller pool of Trebouxia could either be related to a less efficient accumulation system or to a somewhat more efficient Rubisco of this alga compared to $C$. reinhardtii. The latter hypothesis finds support from earlier findings of an inverse relationship between the size of the DIC pool and both the affinity and specificity for $\mathrm{CO}_{2}$ of Rubisco (Badger and Andrews 1987, Palmqvist et al. 1995). Second, in the free-living algae, the external $\mathrm{CO}_{2}$ concentration experienced during growth regulates both the relative strength and the induction/repression of the CCM and its components (Badger and Price 1994). However, since both photosynthesis (Fig. 2) and growth was inhibited in Trebouxia at high $\mathrm{CO}_{2}$ it remains unclear whether the $\mathrm{CCM}$ can be repressed also in this genus. Third, the high activity of periplasmic CA that is induced by low $\mathrm{CO}_{2}$, in for instance $C$. reinhardtii, Chlorella and Scenedesmus (Badger and Price 1994), could not be detected in free-living $T$. erici. Fourth, the subcellular location and the molecular details of internal CA in Trebouxia need to be further studied before we can compare the CAs of this alga with the other CCM algae, which are now known to possess more than one internal CA isozyme (Karlsson et al. 1995, Eriksson et al. 1996).

\section{Why different strategies?}

The absence of a CCM in Coccomyxa has previously been correlated with a relatively more efficient Rubisco of this alga, compared with that of $C$. reinhardtii (Palmqvist et al. 1995). Despite this, photosynthetic $\mathrm{CO}_{2}$ acquisition was more efficient in Trebouxia compared with 
Coccomyxa (Fig. 2C), so the reason(s) for the development of different $\mathrm{CO}_{2}$ acquisition strategies among green algal lichen photobionts still needs to be resolved. Both Coccomyxa and Trebouxia belong to the same algal class, Trebouxiophyceae (Friedl 1995; T. Friedl, personal communication), a class which in recent studies appear to have a monophyletic origin (Friedl 1995). However, Trebouxiophyceae includes a broad range of species with a high degree of both morphological (cf. Friedl 1995) and physiological (Palmqvist et al. 1994b, Máguas et al. 1995, Smith and Griffiths 1996a) variation. Moreover, even though the hypothesis of a multiple origin of lichens was recently suggested also from DNA analysis (Gargas et al. 1995), it is not clear whether Trebouxia and Coccomyxa occurred as photobionts at different stages during lichen evolution. Neither do we know if the presence or absence of a CCM is related to the environmental conditions when the symbiosis first occurred or whether the $\mathrm{CO}_{2}$ acquisition pathway has continued to evolve within the lichen. Still, it is tempting to suggest that Trebouxia with its pyrenoid and higher degree of lichenisation might be the older of the two genera as a lichen photobiont. If so, Coccomyxa may have lost the pyrenoid (Fig 1B,C), developed a Rubisco with a higher affinity and specificity to $\mathrm{CO}_{2}$ (Palmqvist et al. 1995) and gained its $\beta$-type CA (Hiltonen et al. $1995)$ more recently during evolution. This hypothesis is supported by the findings of Smith and Griffiths (1996b), showing that those hornworts (Anthocerotae) that have retained a scattered pyrenoid also possess a CCM. Evidently, we need much more data and a multidisciplinary approach to resolve this problem, including phylogenetic relationships as well as physiological, biochemical (Rubisco) and immunocytological data for more species within Trebouxiophyceae, comparing a broader range of species both with and without a pyrenoid, respectively.

Acknowledgments - We wish to thank Dr Joaquin Moreno for providing the Rubisco antibody and Dr T. Friedl for valuable comments and unpublished data on Coccomyxa phylogeny. Thanks also to T. Hiltonen and J. Karlsson (Dept Plant Physiology, Umeå Univ., Sweden) for provision of unpublished data, CA antibodies and fruitful discussions. This investigation was supported by grants to K. P. and G. S. from the Swedish Natural Sciences Research Council (NFR), a grant for short term stays abroad to A. R. from the Spanish Ministry of Education and Science and financial support (DGYCYT-PB95-0067) to A. R. and C. A.

\section{References}

Ascaso, C., Brown, D. H. \& Rapsch, S. 1988. The effect of desiccation on pyrenoid structure in the oceanic lichen Parmelia laevigata. - Lichenologist 20: 31-39.

, Valladares, F. \& de los Rios, A. 1995. New ultrastructural aspects of pyrenoids of the lichen photobiont Trebouxia (Microthamniales, Chlorophyta). - J. Phycol. 31: 114-119.

Badger, M. R. \& Andrews, T. J. 1987. Co-evolution of Rubisco and $\mathrm{CO}_{2}$ concentrating mechanisms. - In Progress in Photosynthesis Research, Vol. III (J. Biggins, ed.), pp. 601-609. Martinus Nijhoff, Dordrecht. ISBN 90-247-3452-5.
\& Price, G. D. 1994. The role of carbonic anhydrase in photosynthesis. - Annu. Rev. Plant Physiol. Plant Mol. Biol. 45: 369-392.

, Kaplan, A. \& Berry, J. A. 1980. Internal inorganic carbon pool of Chlamydomonas reinhardtii. - Plant Physiol. 66: 407-413.

, Pfanz, H., Büdel, B., Heber, U. \& Lange, O. L. 1993. Evidence for the functioning of photosynthetic $\mathrm{CO}_{2}$-concentrating mechanisms in lichens containing green algal and cyanobacterial photobionts. - Planta 191: 57-70.

Balaguer, L., Valladares, F., Ascaso, C., Barnes, J. D., de los Rios, A., Manrique, E. \& Smith, E. C. 1996. Potential effects of rising tropospheric concentrations of $\mathrm{CO}_{2}$ and $\mathrm{O}_{3}$ on green-algal lichens. - New Phytol 132: 641-652.

Coleman, J. R., Berry, J. A., Togasaki, R. K. \& Grossman, A. R. 1984. Identification of extracellular carbonic anhydrase of Chlamydomonas reinhardtii. - Plant Physiol. 76: $472-477$.

Eriksson, M., Karlsson, J., Ramazanov, Z., Gardeström, P. \& Samuelsson, G. 1996. Discovery of an algal mitochondrial carbonic anhydrase: Molecular cloning and characterisation of a low- $\mathrm{CO}_{2}$ induced polypeptide in Chlamydomonas reinhardtii. - Proc. Natl. Acad. Sci. USA 93: 12031-12034.

Friedl, T. 1995. Inferring taxonomic positions and testing genus level assignments in coccoid green lichen algae: A phylogenetic analysis of $18 \mathrm{~S}$ ribosomal RNA sequences from Dictyochloropsis reticulata and from members of the genus $M y r-$ mecia (Chlorophyta, Trebouxiophyceae C. Nov.). - J. Phycol. 31: 632-639.

- \& Büdel, B. 1996. Photobionts. - In Lichen Biology (T. H. Nash III, ed.), pp. 8-23. Cambridge University Press, Cambridge. ISBN 0-521-45974-5.

Fukuzawa, H., Fujiwara, S., Yamamoto, Y., Dionisio-Sese, M. L. \& Miyachi, S. 1990. cDNA cloning, sequence, and expression of carbonic anhydrase in Chlamydomonas reinhardtii: Regulation by environmental $\mathrm{CO}_{2}$ concentration. Proc Natl. Acad. Sci. USA 87: 4383-4387.

Gargas, A., DePriest, P. T., Grube, M. \& Tehler, A. 1995. Multiple origins of lichen symbioses in fungi suggested by SSU rDNA phylogeny. - Science 268: 1492-1495.

Hewett-Emmett, H. D. \& Tashian, R. E. 1996. Functional diversity, conservation and convergence in the evolution of the $a$-, $\beta$-, and $\gamma$-carbonic anhydrase gene families. - Mol. Phyl. Evol. 5: 50-77.

Hiltonen, T., Karlsson, J., Palmqvist, K., Clarke, A. K. \& Samuelsson, G. 1995. Purification and characterisation of an intracellular carbonic anhydrase from the unicellular green alga Coccomyxa. - Planta 195: 345-351.

Honegger, R. 1991. Functional aspects of the lichen symbiosis. - Annu. Rev. Plant Physiol. 42: 553-578.

Karlsson, J., Hiltonen, T., Husic, H. D., Ramazanov, Z. \& Samuelsson, G. 1995. Intracellular carbonic anhydrase of Chlamydomonas reinhardtii. - Plant Physiol. 109: 533-539.

Lange, O. L., Budel, B., Heber, U., Meyer, A., Zellner, H. \& Green, T. G. A. 1993. Temperate rain forest lichens in New Zealand: High thallus water content can severely limit photosynthetic $\mathrm{CO}_{2}$ gas exchange. - Oecologia 95: 303-313.

Máguas, C., Griffiths, H. \& Broadmeadow, M. S. J. 1995. Gas exchange and carbon isotope discrimination in lichens: Evidence for interactions between $\mathrm{CO}_{2}$-concentrating mechanisms and diffusion limitation. - Planta 196: 95-102.

Nichols, H. W. \& Bold, H. C. 1965. Trichosarcina polymorpha gen. et sp. nov. - J. Phycol. 1: 34

Ögren, E. \& Evans, J. R. 1993. Photosynthetic light-response curves. I. The influence of $\mathrm{CO}_{2}$ partial pressure and leaf inversion. - Planta 189: 182-190.

Palmqvist, K. 1993. Photosynthetic $\mathrm{CO}_{2}$ use efficiency in lichens and their isolated photobionts: The possible role of a $\mathrm{CO}_{2}$ concentrating mechanism. - Planta 191: 48-56.

- \& Badger, M. R. 1996. Carbonic anhydrase(s) associated with lichens: In vivo activities, possible locations and putative roles. - New Phytol. 132: 627-639.

- , Ramazanov, Z. \& Samuelsson, G. 1990. The role of extra- 
cellular carbonic anhydrase for accumulation of inorganic carbon in the green alga Chlamydomonas reinhardtii. A comparison between wild-type and cell-wall less mutant cells. - Physiol. Plant. 80: 267-276.

, Ögren, E. \& Lernmark, U. 1994a. The $\mathrm{CO}_{2}$ concentrating mechanism is absent in the green alga Coccomyxa: A comparative study of photosynthetic $\mathrm{CO}_{2}$ and light responses of Coccomyxa, Chlamydomonas reinhardtii and barley protoplasts. - Plant Cell Environ. 17: 65-72.

_ , Samuelsson, G. \& Badger, M. R. 1994b. Photobiont-related differences in carbon acquisition among green-algal lichens. - Planta 195: 70-79.

- , Sültemeyer, D., Baldet, P., Andrews, T. J. \& Badger, M. R. 1995. Characterisation of inorganic carbon fluxes, carbonic anhydrase(s) and ribulose-1,5-bisphosphate carboxylase-oxygenase in the green unicellular alga Coccomyxa. Comparisons with low- $\mathrm{CO}_{2}$ cells of Chlamydomonas reinhardtii. Planta 197: 352-361.

Peveling, E. \& Galun, M. 1976. Electron microscopical studies on the phycobiont Coccomyxa Schmidle. - New Phytol. 77: 713-718.

Reynolds, S. 1963. The use of lead citrate at high pH as an electron-opaque stain in electron microscopy. - J. Cell Biol. 17: 200-211.

Ronen, R. \& Galun, M. 1984. Pigment extraction from lichens with dimethyl sulphoxide (DMSO) and estimation of chlorophyll degradation. - Environ. Exp. Bot. 24: 239-245.

Smith, E. C. \& Griffiths, H. 1996a. The occurrence of the chloroplast pyrenoid is correlated with the activity of a $\mathrm{CO}_{2}$-concentrating mechanism and carbon isotope discrimination in lichens and bryophytes. - Planta 198: 6-16.

- \& Griffiths, H. 1996b. A pyrenoid-based carbon concentrating mechanism is present in terrestrial bryophytes of the class Anthocerotae. - Planta 200: 203-212.

Sundberg, B., Campbell, D. \& Palmqvist, K. 1997. Predicting $\mathrm{CO}_{2}$ gain and photosynthetic light acclimation from fluorescence yield and quenching in cyano-lichens. - Planta 201: $138-145$. 
This document is a scanned copy of a printed document. No warranty is given about the accuracy of the copy. Users should refer to the original published version of the material. 